\title{
Глава 7.
}

\section{АГРОХИМИЯ И ПОЧВОВЕДЕНИЕ}

\section{ВЛИЯНИЕ УДОБРЕНИЯ ВАSАСОТЕ HА РОСТ И РАЗВИТИЕ VACCINIUM CORYMBOSUM L.}

Божидай Т. Н.

\author{
Республиканское научно-производственное \\ дочернее унитарное предприятие «Институт плодоводства», \\ аг. Самохваловичи, Республика Беларусь, e-mail: tanya_bozhidaj@mail.ru
}

Недостаток питательных веществ на этапе постадаптации может привести к замедлению роста и развития адаптированных растений к условиям ex vitro, что в дальнейшем повлияет на качество посадочного материала, а также на продуктивность растений. Цель исследования - изучить влияние удобрения пролонгированного действия Basacote 6M Plus (COMPO, Германия) на рост и развитие голубики на этапе постадаптации. В результате проведённых исследований определено влияние удобрения пролонгированного действия Basacote $6 \mathrm{M}$ Plus на прирост побегов, побегообразование и площадь листьев. Оптимальным субстратом на данном этапе является смесь верхового торфа и агроперлита $(3: 1)$ с добавлением 1 г/л Basacote 6M Plus.

Ключевые слова: голубика, постадаптация, удобрение, морфологические параметры, Беларусь.

Микроразмножение представителей рода Vaccinium L. является экономически выгодным и рассматривается как один из основных этапов комплексной современной технологии ускоренного производства высококачественного посадочного материала в промышленных объёмах [1-5]. Адаптация растений (1-й этап - адаптация растений-регенерантов к нестерильным условиям, 2-й этап - постадаптация) является последним этапом размножения in vitro.

Недостаток питательных веществ на этапе постадаптации может привести к замедлению роста и развития адаптированных растений к условиям ex vitro, что в дальнейшем повлияет на качество посадочного материала, а также на продуктивность растений.

Включение удобрений пролонгированного действия в состав почвогрунтов при выращивании посадочного материала с закрытой корневой системой оказывает положительное влияние на биометрические показатели растений. Также отмечается, что содержание необходимых растению макро- и микроэлементов при применении удобрений пролонгированного действия более стабильно, что обеспечивает непрерывное их потребление растением [6,7].

Цель исследования - изучить влияние удобрения пролонгированного действия Basacote $6 \mathrm{M}$ Plus (COMPO, Германия) на рост и развитие голубики на этапе постадаптации. 
Глава 7. Агрохимия и почвоведение

Объекты и методы исследований. Исследования проводили в отделе биотехнологии РУП «Институт плодоводства».

Размноженные in vitro растения-регенеранты голубики высокорослой (Vaccinium corymbosum L.) сорта 'Bluecrop' укореняли в условиях ex vitro в мини-парниках $450 \times 200 \times 70$ мм (расстояние между рядами - 10-15 мм, в ряду - 7-10 мм). В качестве субстрата использовали мох Sphagnum L. со слоем (0,5 см) верхового торфа «Двина» (pH 2,5-3,5). Длительность культивирования -8 недель. Укоренение в условиях $e x$ vitro сопровождалось адаптацией растений-регенерантов.

Растения после этапа адаптации высаживали в горшки размером $7 \times 7 \times 7$ см $(0,2$ л).

\section{Варианты опыта:}

- контроль - смесь верхового торфа и агроперлита (3 : 1);

- смесь верхового торфа и агроперлита $(3: 1)+1$ г/л Basacote $(0,2$ г/растение);

- смесь верхового торфа и агроперлита $(3: 1)+2$ г/л Basacote $(0,4$ г/растение);

- смесь верхового торфа и агроперлита $(3: 1)+3$ г/л Basacote (0,6 г/растение).

Условия постадаптации: освещение 2,5-3,0 тыс. лк, температура $+20 \ldots+22^{\circ} \mathrm{C}$, фотопериод $16 / 8$ ч.

Влияние удобрения пролонгированного действия оценивали через каждые 4 недели после посадки растений.

Анализируемые показатели: прирост побегов (см), количество образовавшихся побегов (шт.), длина образовавшихся побегов (см), площадь листьев $\left(\mathrm{cm}^{2}\right)$.

Для расчёта средней площади листьев брали лист из средней части побега каждого растения из трёх повторностей. Площадь листа определяли с помощью Easy Leaf Area [8].

Статистическую обработку проводили в программе Statistica 10, используя ANOVA, дисперсионный анализ, критерий Дункана $(p<0,05)$ для сравнения средних значений $(\mathrm{n}=3)$. Построение графиков проводили в программе Statistica 10 (вертикальные линии - доверительный интервал).

Результаты и их обсуждение. Исследования показали, что спустя 4 недели после посадки растений удобрение пролонгированного действия или не оказало значимого влияния на прирост побегов. Среднее значение прироста побегов было в 4,3 и более раз выше $(\mathrm{p}<0,05)$, чем в контрольном варианте. Растения на субстратах с добавлением 1, 2 и 3 г/л Basacote по приросту (средний прирост побегов - 3,34 $\pm 0,25$ см) значимо не отличались между собой (рис. 1, 2). Такая тенденция прослеживалась и спустя 8-16 недель после посадки. Более активный рост растений во всех вариантах отмечался спустя 16 недель после посадки (рис. 2-4). 


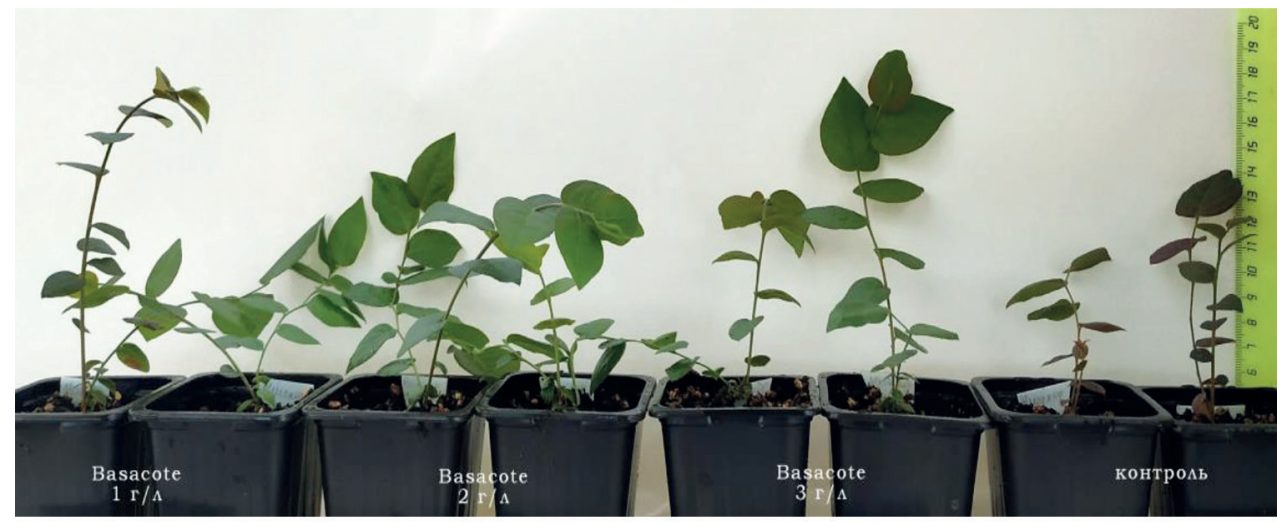

Рис. 1. Растения голубики сорта 'Bluecrop'

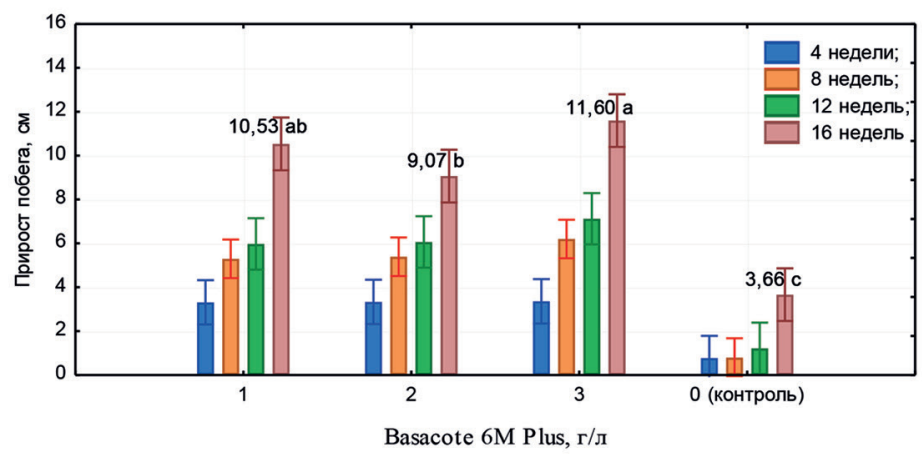

Рис. 2. Влияние

удобрения на прирост побегов голубики

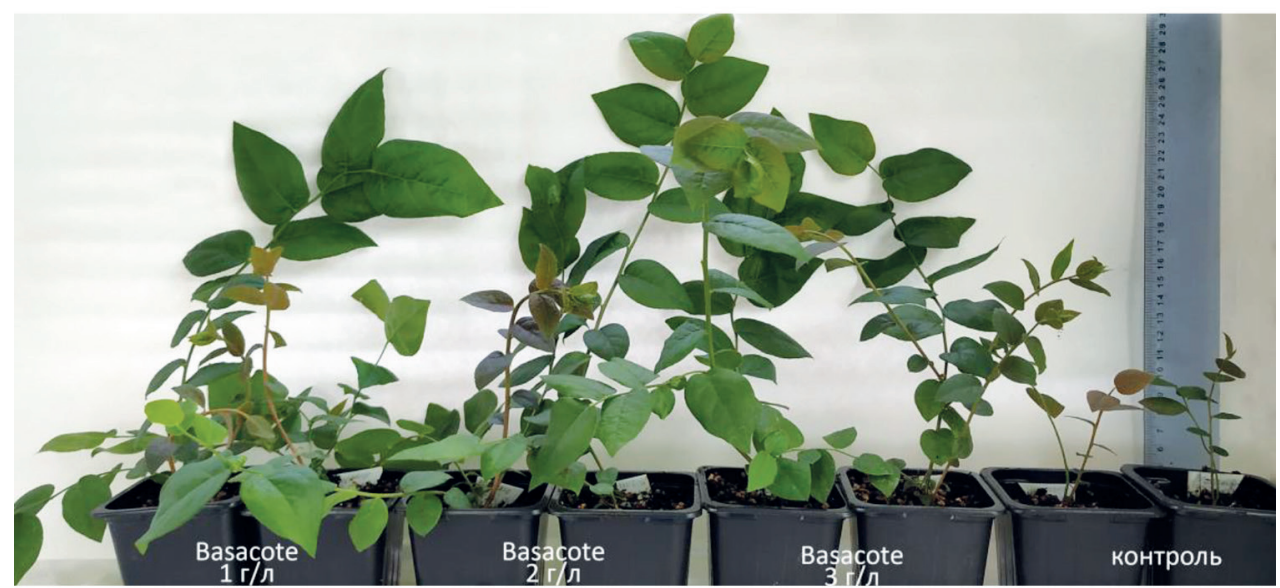

Рис. 3. Растения голубики сорта 'Bluecrop' на этапе постадаптации спустя 8 недель после посадки 


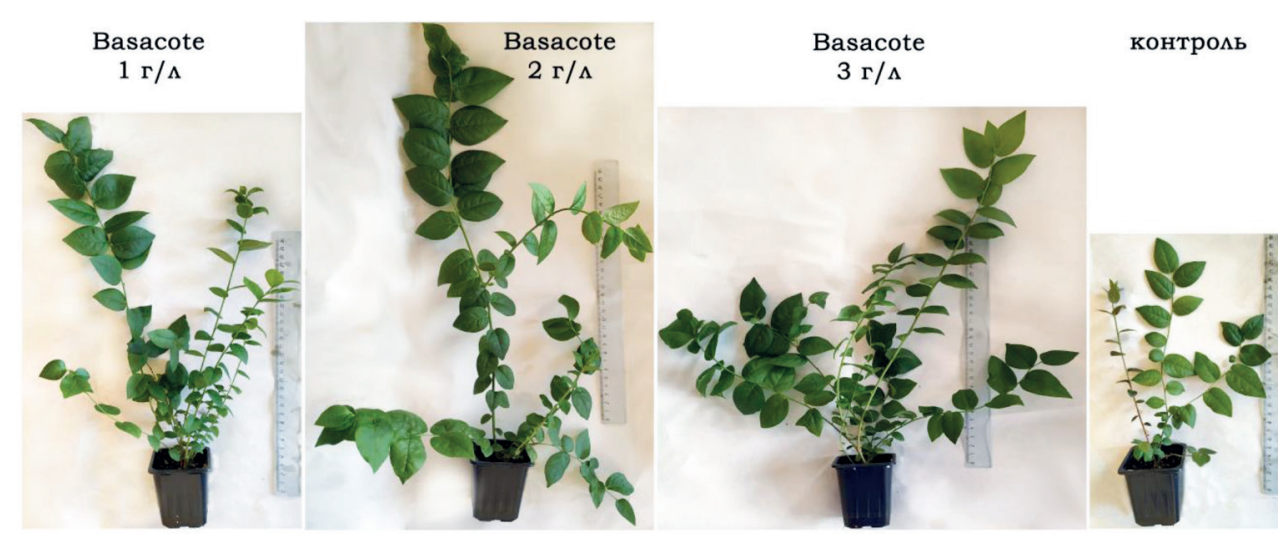

Рис. 4. Растения голубики сорта 'Bluecrop'

на этапе постадаптации спустя 16 недель после посадки

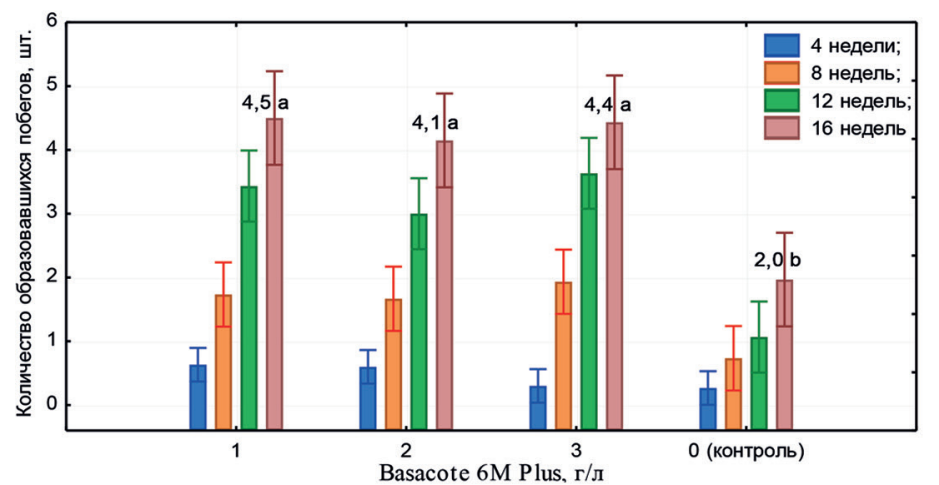

Рис. 5. Влияние

удобрения на побегообразование голубики

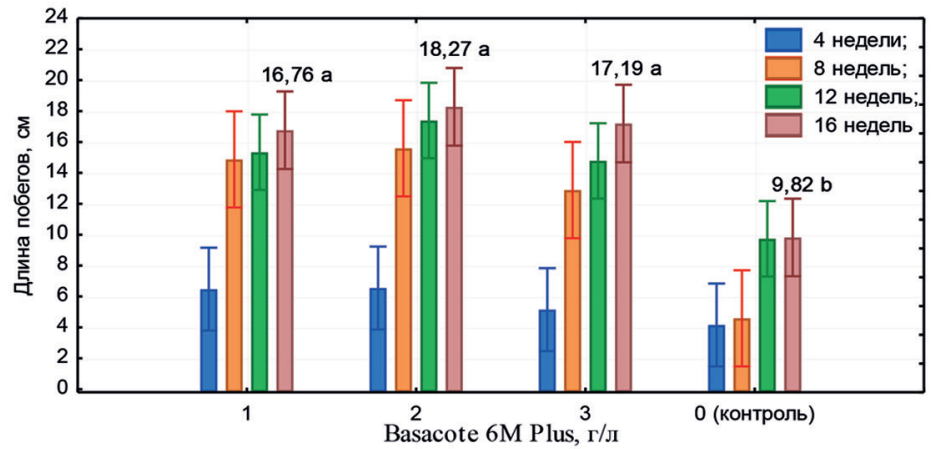

Рис. 6. Влияние

удобрения на длину образовавшихся побегов голубики

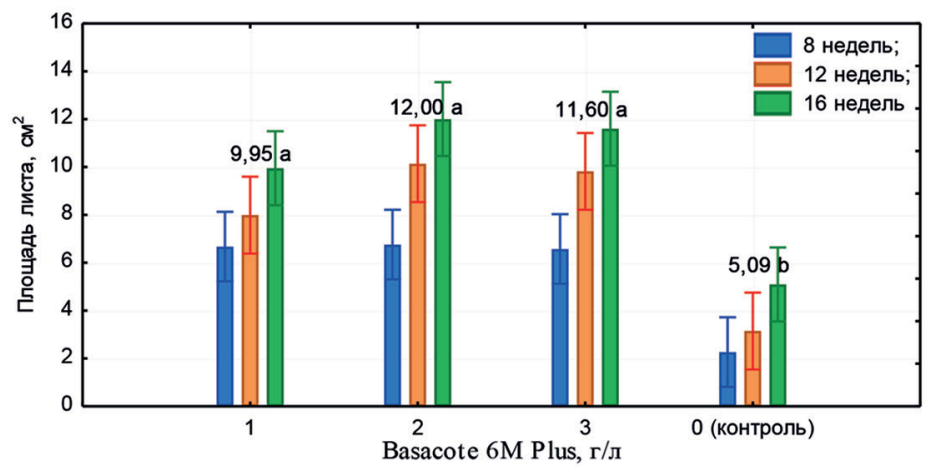

Рис. 7. Влияние удобрения на площадь листьев голубики 
Удобрение оказало значимое ( $<<0,05)$ влияние на количество и длину образовавшихся побегов спустя 8-16 недель после посадки. Растения по количеству и длине побегов на субстрате с добавлением Basacote превосходили $(\mathrm{p}<0,05)$ контрольный вариант. В результате среднее количество образовавшихся побегов спустя 16 недель после посадки на субстрате с добавлением удобрения составило в среднем 4,4 $\pm 0,15$ шт., средняя длина - 21,97 $\pm 0,71$ см (рис. 5, 6).

Спустя 8, 12 и 16 недель был проведён анализ средней площади листьев голубики (рис. 7). Растения на субстратах с различным содержанием Basacote по средней площади листьев статистически значимо не отличались друг от друга, при этом превосходили $(\mathrm{p}<0,05)$ контрольный вариант в 2,0 и более раз.

Заключение. Удобрение пролонгированного действия Basacote 6M Plus показало высокую эффективность на этапе постадаптации и привело к усилению ростовых процессов растений голубики сорта 'Bluecrop'. По изучаемым показателям растения на субстратах с различным содержанием Basacote статистически значимо не отличались друг от друга, следовательно, оптимальным субстратом на данном этапе является смесь верхового торфа и агроперлита (3 : 1) с добавлением 1 г/л Basacote 6M Plus.

\section{Библиографический список}

1. Решетников В.Н., Антипова Т.В., Филипеня В.Л. Некоторые аспекты микроклонального размножения голубики высокой и брусники обыкновенной // Плодоводство: научные труды. - 2007. - Т. 19. - С. 209-215. - ISSN 0134-9759.

2. Debnath S.C. Propagation of Vaccinium in vitro: a review // International Journal of Fruit Science. - 2006. - Vol. 6. - № 2. - P. 47-71. - ISSN 1553-8621.

3. Ostrolucka M.G., Gajdosova A., Ondruskova E., Libiakova G. In vitro propagation of several Vaccinium corymbosum L. and Vaccinium vitis-idaea L. cultivars // Agronomijas Vestis. - 2009. - № 12. - P. 75-80. - ISSN 1691-3485.

4. Litwinczuk W. Micropropagation of Vaccinium sp. by in vitro axillary shoot proliferation // Protocols for micropropagation of selected economically-important horticultural plants / eds. M. Lambardi et al. - 2013. - Vol. 5. - C. 63-76. - ISSN 1064-3745.

5. Meiners J., Schwab M., Szankowski I. Efficient in vitro regeneration systems for Vaccinium species // Plant Cell, Tiss. Organ Cult. - 2007. - Vol. 89. - Issue 2-3. - P. 169-176. - ISSN 0167-6857.

6. Трещевская Э.И., Цепляев А.Н. Применение удобрения пролонгированного действия при выращивании посадочного материала по системе pot-in-pot // Труды Санкт-Петербургского научно-исследовательского института лесного хозяйства. 2017. - № 4. - С. 48-55. - doi: 10.21178/2079-6080.2017.4.48.

7. Глаз Н.В., Уфимцева Л.В. Перспективы применения удобрения пролонгируемого действия Basacote при выращивании посадочного материала в контейнерах // Агрохимический вестник. - 2018. - № 3. - С. 12-14. - doi: 10.24411/0235-2516-2018-10003. 8. Easlon H.M., Bloom A.J. Easy Leaf Area: automated digital image analysis for rapid and accurate measurement of leaf area [Electronic resource] // Applications in Plant Sciences. 2014. - Vol. 2. - № 7. - doi: 10.3732/apps.1400033. 


\title{
INFLUENCE \\ OF FERTILIZER BASACOTE \\ ON GROWTH AND DEVELOPMENT \\ OF VACCINIUM CORYMBOSUM L.
}

\author{
Bozhyday T. N. \\ Republican Research and Production \\ Unitary Enterprise "Institute of Fruit Growing", \\ Samokhvalovichi, Republic of Belarus, mail: tanya_bozhidaj@mail.ru
}

Nutrient deficiencies at the stage of post-adaptation can slow down growth and development of plants ex vitro and can adversely affect the quality of planting material, as well as the productivity of plants. The aim of the research was to evaluate the influence of fertilizer Basacote 6M Plus (COMPO, Germany) on growth and development of blueberry at the stage of post-adaptation. The influence of fertilizer Basacote 6M Plus with the prolonged action on shoot growth, shoot formation and leaf area is determined. The most acceptable substrate at this stage is peat:agroperlite $(3: 1)$ with Basacote $6 \mathrm{M}$ Plus $(1 \mathrm{~g} / \mathrm{l})$.

Key words: blueberry, post-adaptation, fertilizer, morphological parameters, Belarus. 